E3S Web of Conferences 1, 34002 (2013)

DOI: $10.1051 / \mathrm{e} 3 \operatorname{sconf} / 20130134002$

(c) Owned by the authors, published by EDP Sciences, 2013

\title{
Absence of mercury effects on fish populations of boreal reservoirs despite 3 to 6 fold increases in mercury concentrations
}

\author{
R. Schetagne ${ }^{1}$ and J. Therrien ${ }^{2}$ \\ ${ }^{1}$ Environment Department, Hydro-Québec Production, Montreal, Québec, Canada, Schetagne.Roger@hydro.qc.ca \\ ${ }^{2}$ GENIVAR inc, Environmental Consultants, Québec, Québec, Canada, jean.therrien@genivar.com
}

\begin{abstract}
At the La Grande hydroelectric complex located in northern Quebec, Canada, mercury concentrations were measured in over 25000 fish as part of an ongoing environmental effects monitoring program. Five fish species were monitored over a 30-year period: the non-piscivorous lake whitefish (Coregonus clupeaformis) and longnose sucker (Catostomus catostomus) and the piscivorous northern pike (Esox lucius), walleye (Sander vitreus) and lake trout (Salvelinus namaycush). Total mercury concentrations were measured by standard cold vapour atomic absorption spectrophotometry. Fish population characteristics, such as fishing yields, growth rates and condition factors were also monitored over a 20 -year period. In reservoirs, mercury concentrations in all species increased rapidly after impoundment, peaking after 5 to 9 years in non-piscivorous fishes, and after 9 to 11 years in piscivorous species, at levels 3 to 6 times those measured in surrounding natural lakes, then significantly and gradually declined. Concentrations in most species have returned to levels typical of natural lakes, 10 to 30 years after flooding. Despite such increases, the monitored fish showed no mercury-related ill effects at the population level. For most species, increases were observed in fishing yields (by factors ranging from 2 to over 20), in growth rates and in condition factors (for more than a decade). The fishing yield increase was highest for northern pike of the Robert-Bourassa Reservoir, for which the highest average mercury concentrations were measured $\left(3.28 \mu \mathrm{g} \mathrm{g}^{-1}\right.$ (ww) for $700-\mathrm{mm}$ fish). The biological boom usually observed after reservoir impoundment, resulting from increased nutrients, may have prevented potential mercury-related ill effects.
\end{abstract}

Key words: Mercury, Reservoirs, toxicity, fish populations

\section{Introduction}

Mercury, in the organic form of methylmercury, bioaccumulates in fish primarily through dietary uptake. The level of bioaccu- mulation is a function of age, species, and trophic level. Several studies have addressed the potential effects of mercury in the environment and its impact on fish. These studies were primarily carried out in a laboratory, with mercury concentrations generally much higher than those occurring in natural environments, although some were done in the field using concentrations similar to those occurring in natural environments. Effects reported range from changes in behavior to reduced growth and condition factor. Effects on reproduction have also been found in laboratory experiments, at environmentally relevant concentrations ( $<1$ to $2.37 \mu \mathrm{g} \mathrm{g}^{-1}$, ww in muscle). Reproduction effects from field studies were usually inferred from effects on organs or on embryonic development, but no reproduction impairment has been directly observed in the wild.

Reservoir impoundment often causes an increase in mercury concentration along the food chain and ultimately in fish (Lucotte et al., 1999). At the La Grande hydroelectric complex, 5 large reservoirs were impounded between 1978 and 1984. Monitoring of fish populations and of mercury levels in fish were carried out from 1978 to 2000.

Mercury-related effects were established for individual fish but never confirmed at the fish population level, with the exception of cases of industrial pollution. The major objective of this paper is to verify if the post-impoundment increases in fish mercury concentrations, at levels up to 3 to 6 times those in natural surrounding lakes, caused any mercury-related effects in fish at the population level.

\section{Materials and Methods}


At the La Grande complex, fish populations were sampled annually from 1978 to 1984, and every four years afterward, from 1987 to 1999. Sampling was done at 16 stations ( 5 in Robert- Bourassa Reservoir, 4 in Opinaca Reservoir, 4 in Caniapiscau Reservoir, and 3 in natural reference lakes), with multifilament gillnets (stretched mesh ranging from 2.5 to $10.2 \mathrm{~cm}$ ). Nets were set for 24 or $48 \mathrm{hr}$ periods, but were visited every day, for a global fishing effort of 4 to 5 days per station per year. The fish were identified, counted, measured, weighted, and sex and maturity were determined.

For a given day and station, catches of all sampling nets were averaged and expressed as fishing yields in number of fish per net-day (catch per unit of effort CPUE). The monthly CPUE were then averaged to obtain CPUE for a given year.

Bone structures were also taken for age determination on a subsample of fish. Age data were used to generate growth curves with the von Bertalanffy equation $\left(\right.$ Length $=\operatorname{Lmax}\left(1-\mathrm{e}^{(-\mathrm{k}(\mathrm{t}-\mathrm{t} 0))}\right)$.

Changes in the Fulton fish condition factor $(\mathrm{K}=$ Weight $(\mathrm{g}) \times 10^{5} /$ Length $\left.(\mathrm{mm})^{3}\right)$ in modified and reference environments were compared using individuals of the most abundant length-classes for each species, to eliminate effects of inter-annual variations in length distribution. ANOVAs and SNK tests $(\alpha=0.05)$ were used to compare annual means in condition factors for a given environment between pre-impoundment and post-impoundment years.

Samples of $50 \mathrm{~g}$ of flesh were taken for mercury analysis on a subsample of fish (usually 30 fish per species, per station, per year, well distributed according to length). Total mercury in fish flesh (muscle), reported in $\mu \mathrm{g} \mathrm{g}^{-1}$ of wet weight, was analyzed using the standard cold-vapor atomic absorption spectrophotometry. A subset of methylmercury analyses showed that most of the mercury was in the methylmercury form, with average proportions ranging from 97 to $100 \%$. Statistical analysis of temporal and spatial trends was carried out using polynomial regression analysis with indicator variables (Tremblay et al., 1997). Comparisons were made using standard lengths corresponding to average lengths in the catches, which correspond, for all species, to lengths for which all fish were mature.

\section{Results and Discussion}

\section{Mercury increase}

Following impoundment, significant $(\alpha=0.05)$ temporary increases were measured in total mercury concentrations of all fish species caught in the three monitored reservoirs. Non piscivorous species showed increases varying by factors ranging from 3 to 6 depending on species and reservoir (see Figure 2 presented with condition factor). Mercury levels in 400-mm lake whitefish increased from $0.11 \mu \mathrm{g} \mathrm{g}^{-1}$ in natural conditions to maximums of 0.43 to $0.52 \mu \mathrm{g} \mathrm{g}^{-1}$, depending on the reservoir, after 4 to 9 years.
Piscivorous species showed similar increase factors. In 700-mm northern pike, total mercury levels increased from $0.59 \mu \mathrm{g} \mathrm{g}^{-1}$ in natural lakes to maximums of 2.29 to $3.28 \mu \mathrm{g} \mathrm{g}^{-1}$, after 10 to 11 years). For walleye of $400 \mathrm{~mm}$ in length, mercury levels increased from $0.60 \mu \mathrm{g} \mathrm{g}^{-1}$ in natural lakes to maximums of 2.05 to $2.76 \mu \mathrm{g} \mathrm{g}^{-1}$, after 10 to 11 years. In $600-\mathrm{mm}$ lake trout, the mean concentration in natural lakes was $0.73 \mu \mathrm{g} \mathrm{g}^{-1}$ and reached a maximum of $2.08 \mu \mathrm{g} \mathrm{g}^{-1}$ in Caniapiscau Reservoir, 9 years after flooding (see Figure 2 presented with condition factor).

Mercury levels then gradually decreased to background values after 10 to 30 years for most fish species. It has been shown that the post- impoundment increase in mercury levels is due to bacterial decomposition of flooded organic matter that transforms the inorganic mercury contained in this matter into methylmercury, a form that is highly assimilated by aquatic organisms, biomagnified through the food chain and reaches maximum concentrations in piscivorous fish. The increase is temporary however, as the readily decomposable organic matter is rapidly depleted (Lucotte et al., 1999).

\section{Fish population abundance}

During these periods of increased fish mercury levels, fishing yields also showed statistically significant $(\alpha=0.05)$ increases in all three reservoirs, for most species and for the fish community as a whole. This global increase in fishing yields was also observed in more than 100 reservoirs and is associated with the flooding of organic matter, which releases nutrients to the water column. This produces what is called a temporary biological boom, as the nutrient increase stimulates phytoplankton production which in turn stimulates zooplankton production, with positive effects up to fish populations.

The increase in fish mercury levels did not impair fish relative abundance, as maximum mercury levels were often associated with maximum CPUE for all species in the three monitored reservoirs. For example, northern pike CPUE increased markedly in all reservoirs (by factors ranging from 3.8 to 9.4), and values greater than before impoundment and reference lake values were often obtained for the years where maximum or near maximum mercury levels were measured (Table 1).

For the non-piscivorous lake whitefish, CPUE were positively correlated with total phosphorus and chlorophyll $a$ concentrations, as well as with zooplankton biomass. This biological boom is also temporary, as is the mercury increase, as the readily decomposable organic matter is rapidly depleted.

Fish growth

In the three reservoirs, growth rates of all the main species were higher after impoundment (see examples in Figure 1). Significant increases $(\alpha=0.05)$ were found at 
Table 1. Mercury concentration, and fishing yield for northern pike in La Grande reservoirs.

\begin{tabular}{|c|c|c|c|c|c|c|}
\hline \multirow{5}{*}{ Year } & \multicolumn{2}{|c|}{$\begin{array}{c}\text { Robert-Bourassa } \\
\text { Reservoir }\end{array}$} & \multicolumn{2}{|c|}{$\begin{array}{r}\text { Opinaca } \\
\text { Reservoir }\end{array}$} & \multicolumn{2}{|c|}{$\begin{array}{c}\text { Caniapiscau } \\
\text { Reservoir }\end{array}$} \\
\hline & & CPU & & CPU & & $\mathrm{CPU}$ \\
\hline & Total Hg & E & Total Hg & $\mathrm{E}$ & Total $\mathrm{Hg}$ & E \\
\hline & $\left(\mu \mathrm{g} \mathrm{g}^{-1}\right)$ & $\mathrm{F} / \mathrm{n} / \mathrm{d}$ & $\left(\mu \mathrm{g} \mathrm{g}^{-1}\right)$ & $\mathrm{F} / \mathrm{n} / \mathrm{d}$ & $\left(\mu \mathrm{gg}{ }^{1}\right)$ & $\mathrm{F} / \mathrm{n} / \mathrm{c}$ \\
\hline & & $*$ & & & & \\
\hline 1978 & 0.59 & 1.0 & 0.59 & 1.7 & & \\
\hline 1979 & & 0.2 & & & & \\
\hline 1980 & & 0.7 & & 1.0 & 0.55 & 0.2 \\
\hline 1981 & & 2.8 & & 1.4 & & 0.5 \\
\hline 1982 & 1.27 & 5.9 & & 3.8 & & 1.2 \\
\hline 1983 & & 4.7 & & 4.3 & & \\
\hline 1984 & 2.66 & 5.2 & 2.22 & 6.1 & & \\
\hline 1985 & & & & & & \\
\hline 1986 & 2.39 & & 1.60 & & & \\
\hline 1987 & & & & & 0.89 & 4.7 \\
\hline 1988 & 3.21 & 5.4 & 1.93 & 6.4 & & \\
\hline 1989 & & & & & 1.33 & \\
\hline 1990 & 3.28 & & 2.91 & & & \\
\hline 1991 & & & & & 1.74 & 0.7 \\
\hline 1992 & 3.22 & 1.1 & 2.62 & 2.4 & & \\
\hline 1993 & & & & & 2.29 & 1.0 \\
\hline 1994 & 2.95 & & 2.53 & & & \\
\hline 1995 & & & & & 2.07 & 1.9 \\
\hline 1996 & 2.49 & 2.0 & 2.27 & 3.4 & & \\
\hline 1997 & & & & & 1.94 & \\
\hline 1998 & 2.31 & & & & & \\
\hline 1999 & & & & & 1.88 & 2.1 \\
\hline 2000 & 2.18 & & 1.69 & & & \\
\hline
\end{tabular}

Note: in grey, pre-impoundment years.

*CPUE : catch per unit of effort, in number of fish / net / day

young ages for almost all species in all reservoirs, an indication of the increased growth in the fishes born during or shortly after the impoundment, as a consequence of the biological boom mentioned earlier. This predator growth increase phenomenon has been often seen after impoundment for piscivorous species, such as northern pike and walleye, and would result from the density increases in prey.

For the fishes of the three monitored reservoirs, growth rate patterns show no relation with mercury levels, as growth rates of all species, during and after peak mercury levels, remained comparable or higher than those obtained before impoundment (see examples in Figure 1). Indeed, growth rates were still high 16 to 21 years after reservoir impoundment.

The data presented in figure 1 clearly show that in the context of reservoir impoundment, where increased nutrients produce increased biological production, 3 to 6 fold increases in mercury levels did not impair growth rates.

\section{Fish condition}
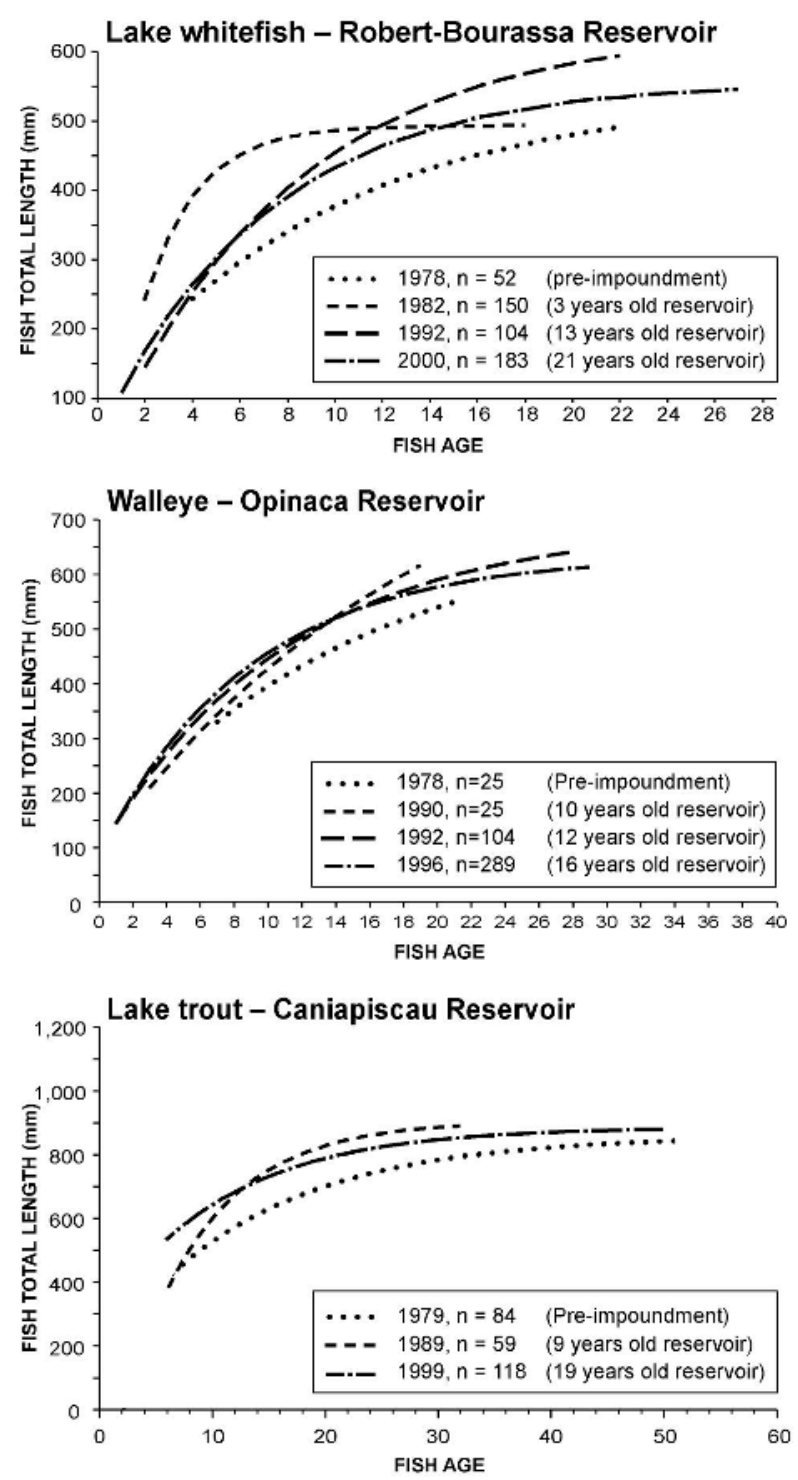

Figure 1 Annual von Bertalanffy growth curves for the major fish species in three reservoirs

Figure 2, showing examples of the evolution of fish condition factors in La Grande reservoirs, shows post-impoundment increases for all species. The evolution of fish condition factors usually closely followed the pattern of change in chlorophyll $a$, an indicator of the nutrient and phytoplankton biomass increases resulting from the decomposition of readily decomposable flooded organic matter (Lucotte et al., 1999).

For the non-piscivorous lake whitefish (figure $2 \mathrm{a}$ ), the condition factor curves were usually synchronised with mercury concentration curves, peak condition values were often associated with peak mercury values. but with a slightly more rapid decrease in condition factors.

For the piscivorous walleye of Robert- Bourassa reservoir (Figure 2b), the initial increases in condition factor, which again closely follows the chlorophyll $a$ upsurge (Lucotte et al., 1999), are not synchronised with the increase in mercury levels, and the peak mercury 
a) Lake whitefish - Robert-Bourassa Reservoir

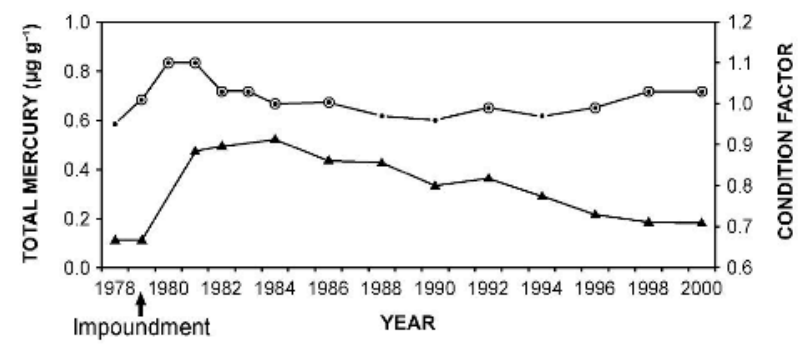

b) Walleye - Opinaca Reservoir

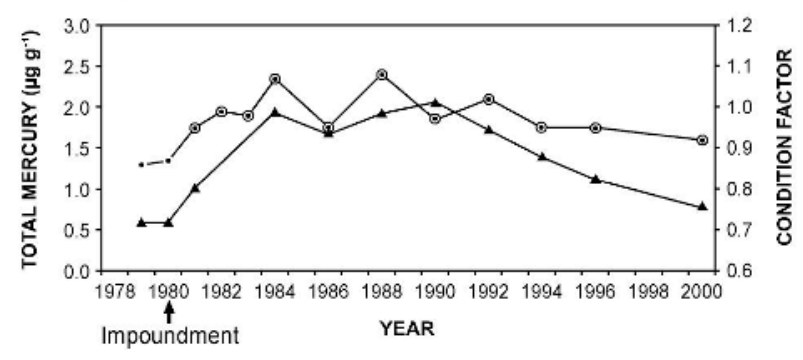

c) Lake trout - Caniapiscau Reservoir
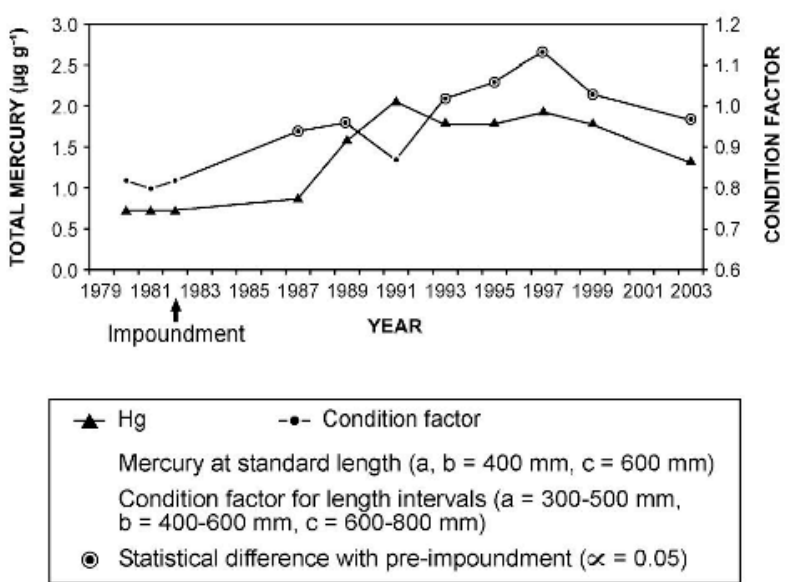

Mercury at standard length $(a, b=400 \mathrm{~mm}, c=600 \mathrm{~mm})$ Condition factor for length intervals $(a=300-500 \mathrm{~mm}$, $\mathrm{b}=400-600 \mathrm{~mm}, \mathrm{c}=600-800 \mathrm{~mm}$ )

- Statistical difference with pre-impoundment $(\alpha=0.05)$

Figure 2 Annual mercury concentration and condition factor of fish species in the La Grande reservoirs

levels are observed well after peak condition factors. Mercury levels in predators usually peak after that of non-piscivorous species, as the mercury must first accumulate in the prey, to be later observed in the predator (Lucotte et al., 1999).

Figure $2 \mathrm{c}$ illustrates the patterns of evolution of condition factors and mercury concentrations in lake trout of the Caniapiscau Reservoir. It shows that, with the exception of the 1991 values which are unusually low in both the reservoir and the reference lake, condition factors closely follow the mercury concentration curve, with higher condition values associated with higher mercury values, and condition remains higher than pre-impoundment values. So again, the postimpoundment evolution in condition factors shows no mercury-related effect, as higher fish mercury levels did not prevent increases in condition factors, which remained higher or equal to pre-impoundment values for nearly two decades.

\section{Conclusion}

Our results do not show mercury-related ill effects on fishing yields, fish growth rates and fish condition factors at the population level, in the context of northern reservoir impoundments, despite temporary 3 to 6 fold increases in fish mercury levels. Such high mercury levels did not prevent significant post-impoundment increases in these fish population good-health indices. The increase in nutrients and primary and secondary production related to the flooding of forest soils and vegetation, which has positive effects on fish populations, may have prevented potential mercury-related ill effects.

\section{Acknowledgements}

This paper was made possible by the extensive environmental effects monitoring carried out by Hydro-Québec at the La Grande hydroelectric complex.

\section{References}

Lucotte M, Schetagne R, Thérien N, Langlois C, Tremblay A, Mercury in the Biogeochemical Cycle: Natural Environments and Hydroelec- tric Reservoirs of Northern Québec. Berlin: Springer. 1999. 334 p.

Tremblay G., Legendre P, Verdon R, Doyon J.-F, Schetagne R. Polynomial regression analysis with indicator variables for the interpretation of monitoring data on mercury levels in fish. Biogeochemistry 1997; 40:189-201. 